Miia Siutila

FM, mediatutkimus, Turun yliopisto

Ellinoora Havaste

FM, mediatutkimus, Turun yliopisto

\title{
Reddit-yhteisön suhtautuminen naisiin e-urheilijoina
}

Elektroninen urheilu (eng. esports), tai e-urheilu, on järjestäytynyttä, usein jopa ammattimaista, kilpailullista videopelaamista, joko verkossa tai yhä useammin paikan päällä peliturnauksissa. Se on nopeasti kasvava urheilumuoto, joka on jo maailmanlaajuisesti valtavirtaa. Vuonna 2018 yhteenlasketut e-urheilun voittosummat saattavat ylittää jopa 900 miljoonaa Yhdysvaltain dollaria (Statista 2018a) ja katsojamäärien on ennustettu kohoavan 380 miljoonaan henkilöön (Statista 2018b). Suomessakin e-urheilu on nuorten miesten keskuudessa toiseksi seuratuin laji heti jääkiekon jälkeen (Korhonen 2017), ja sitä voi seurata esimerkiksi Ylen suorina lähetyksinä. Lajissaan pätevät pelaajat voivat myös hakea Puolustusvoimien Urheilukouluun tai osallistua e-urheiluun keskittyviin koulutuksiin niin lukioissa, ammattikouluissa kuin ammattikorkeakouluissakin. Tänä vuonna suomalaiset ammattilaispelaajat ovat menestyneet maailmalla loistavasti Topias "Topson" Taavitsaisen ja Jesse "JerAx" Vainikan voitettua Dota 2 -pelin maailmanmestaruuden muun joukkueensa kanssa sekä Joona "Serral" Sotalan katkaistua korealaisten 20-vuotisen voittoputken Starcraft-pelisarjan MM-kilpailuissa.

Nopeasta kasvusta huolimatta, tai luultavammin sen seurauksena, lajissa esiintyy itsepintaista sukupuolten välistä epätasa-arvoa. Miehet ovat enemmistö niin e-urheilun pelaajissa, katsojissa kuin alan toimijoissa, vaikka naiset ovat yhä runsaammin edustettuina nk. kasuaalipelaajina, striimaajina ja e-urheilutapahtumien yleisössä sekä katsojina että vedonlyöjinä (Gainsbury et al. 2017). Naiset ovat toki aina olleet läsnä e-urheilun kentällä monissa rooleissa ja naisten vaikutus näkyy vahvasti muun muassa erilaisten naisille suunnattujen kilpailujen perustamisessa ja yhdenvertaisuuden lisäämisessä (Cassell ja Jenkins 1998). Naisten kilpailujen taso on kuitenkin matalampi, rahapalkinnot pienempiä ja niiden saama julkisuus vähäisempää kuin miesvaltaisten yleisten kilpailujen - siitä huolimatta, että naisten kilpailuja pelataan myös osana virallisia avoimia turnajaisia ja jopa samalla nimellä. Arvostetumpaa naisten elektronista urheilua kohti edetään hitaasti: esimerkiksi vuonna 2017 Australian Esports Media Group järjesti kunnianhimoisen Counter-Strike: Global Offensive -ammuntapelin naisten Oseanian liigan, jonka ensimmäisen kauden lopputurnauksessa oli jaossa yhteensä 10000 Australian dollaria (Citizen 2017).

Myös harrastelijapiireissä naisiin kohdistuu erilaisia odotuksia pelaajina kuin miehiin (Beavis and Charles 2007; Vesterby 2005; Maric 2011). He jäävät usein sivurooleihin osallistuessaan alan tapahtumiin (Taylor, Jenson \& Castell 2009; Ratan et al. 2015) ja saavat miehiä negatiivisemman vastaanoton pelatessaan verkossa (Kuzznekoff \& Rose 2013; Cote 2017). Varsinkin e-urheilussa esiintyvä häirintä on 
tarpeen nähdä osana laajempaa naisten kokemaa häirintää videopelialalla (Massanari 2015; Gray et al. 2017). E-urheilun ja sen ympärille kehittyneiden rakennelmien ja yhteisöjen räjähdysmäinen kasvu tuo mukanaan haasteita, jotka kasvattavat ja vahvistavat pelialan epätasa-arvoa sukupuolten välillä.

Yksi näistä haasteista on e-urheiluyhteisöjen suhtautuminen naisiin kanssapelaajina, katsojina ja toimijoina. Tutkimme tässä katsauksessa Reddit-sivustolla vuonna 2016 käytyä keskustelua Team YP -naisjoukkueen julkistamistiedotteen ympärillä. Olimme kiinnostuneita löytämään keskeisiä stereotypioita ja mielikuvia, joita tämän päivän e-urheiluyhteisössä on naispelaajista, naisille tarkoitetuista kilpailuista ja naisjoukkueista. Naisten asema varsinkin ammattipelaajina on hyvä mittari yhteisön näkemyksiin naisten mahdollisuuksien edistämisestä e-urheilussa ylipäänsä. Tässä katsauksessa keskitymme siihen mitä saimme selville sukupuoliodotuksista ja -rooleista e-urheilun historian valossa.

\section{Tapaus League of Legends -subreddit ja Team YP}

Kesäkuussa 2016 pornografisen YouPorn-sivuston omistama Team YP tiedotti kiinnittäneensä League of Legends -e-urheilupeliin (Riot Games 2009-) naisjoukkueen. Yahoo! Sports -sivustolla julkaistu tiedote (Cocke 2016) nousi esiin 13. kesäkuuta 2016 r/leagueoflegends-alaosiossa (eng. subreddit). Tiedotteesta lähteneessä ketjussa oli yhteensä 910 kommenttia. ${ }^{1}$ Tutkimme keskusteluketjun avulla, kuinka merkittävä verkossa toimiva kilpapeli- ja e-urheiluyhteisö r/leagueoflegends suhtautuu naisiin e-urheilupelaajina. Reddit on keskeinen paikka League of Legends -pelin, lempinimeltään LoL, yhteisölle, sillä r/leagueoflegends on ahkerammassa käytössä kuin pelin virallinen keskustelufoorumi. Keskusteluketjussa nousi esiin yhteisössä vallitsevia keskeisiä mielikuvia ja stereotypioita naispelaajista, naisille tarkoitetuista kilpailuista ja naisjoukkueista. Osa näistä mielikuvista liittyy erityisesti LoL:iin alalajina ja osa laajempaan keskusteluun naisurheilijoista ja naisten kilpailuista yleensä.

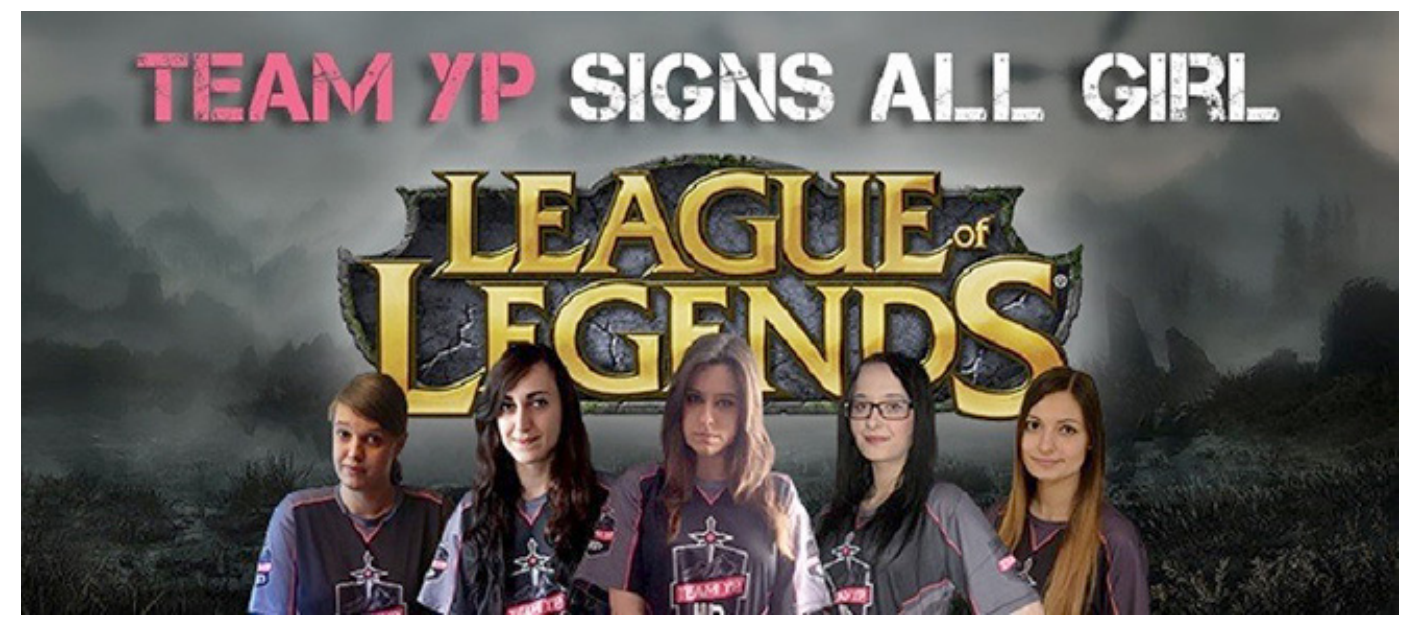

Joanna "Myshka" Pigla, Tanja "Escape" Reither, Laura "Aryenzz" Muñoz, Marlies "Maestra" Brunnhofer ja Patrycja "Reniferka" Krum poseeraavat Team YP:n tiedotteessa joukkueen pelipaidoissa. Kuva: Team YP (13.6.2016).

\footnotetext{
1 Lukumäärä elokuussa 2017 arkistoidussa ketjussa.
} 
Redditin toiminta perustuu linkkien ja muun verkkosisällön jakamiseen, mutta se on monilta osin myös keskustelufoorumi. Alustalle julkaistua sisältöä voivat toiset käyttäjät paitsi kommentoida myös pisteyttää. Erilaisten subreddit-osioiden ympärille on muodostunut omistautuneita yhteisöjä, jotka noudattavat erilaisia tapakulttuureja. Redditin tapakulttuuria hallitsee Adrienne Massanarin mukaan ensisijaisesti maskuliininen nörttikulttuuri, jossa käyttäjän normi on "valkoinen, vammaton, nuori heteroseksuaalinen cis-sukupuolinen mies" jolla on teknistä osaamista (Massanar 2015, 129). Hän myös näkee Redditin tapakulttuurin rohkaisevan käyttäjiään tuottamaan runsaasti erilaista verkkosisältöä meemeistä ja vitseistä groteskeihin valokuviin ja vilpittömiin kommentteihin. Massanarin mukaan sivuston yhteisöllisyyttä vahvistaa myös uudelleen kertomisen kulttuuri, jossa tarinoiden ja meemien toisto on luovaa leikkiä yhteisön jäsenten välillä. (Massanari 2015, 19-25.) Jenny Kennedy, James Meese ja Emily van der Nagel (2016) taas argumentoivat tapakulttuurin rakentuvan ensisijaisesti pisteytyksen (eng. upvote) ja sivuston algoritmien toiminnan ympärille. Keskusteluketjun korkea pistemäärä muun muassa nostaa ketjua sen subreddit-osion etusivulle. Kiinnostavaa valitsemassamme keskusteluketjussa olikin sen alhainen pistemäärä (483 pistettä) vastauksien määrään verrattuna. Suositut ketjut r/leagueoflegends-alaosiossa saattavat saada kymmeniä tuhansia pisteitä, kuten pelin aprillipilan keskusteluketju vuonna 2017, joka sai yli 69000 pistettä. Pisteytys kertookin osaltaan aiheen kiistanalaisuudesta, sillä Redditin käyttäjät antavat usein pisteitä omia mielipiteitään tukeville kommenteille.

Tutkimuksemme koostui kahdesta osasta. Ensin teimme sisältöanalyysin lukemalla kaikki kommentit yksitellen läpi ja jakamalla ne ryhmiin aiheen tai funktion perusteella (vrt. Hsieh \& Shannin 2005). Löysimme sisältöanalyysin avulla kahdeksan eri ryhmää. Tämän jälkeen keskityimme lähiluvun (vrt. Brummett 2009) ja kvantitatiivisen analyysin avulla kommenttien keskeisiin mielikuviin ja stereotypioihin, joita naispelaajiin ja naisten joukkueisiin liitettiin. Seuraavaksi kartoitimme ensisijaisesti sitä, miten nämä stereotypiat ja mielikuvat rakentuivat kommenttiketjussa, mitä keskustelijat niiden avulla halusivat kertoa ja miten ne liittyivät naisten asemaan e-urheilun kentällä yleisesti. Ketjun kommentit on käännetty vapaasti englannista suomeksi omasta toimestamme.

\section{E-urheilun meritokratia}

Monen keskustelijan mielestä e-urheilun kenttä oli jo valmiiksi tasa-arvoinen paitsi sukupuolen myös pelaajien muiden ominaisuuksien osalta. Ainoa ominaisuus, jonka nähtiin vaikuttavan pelaajan menestykseen, oli taito. Erityisesti meritokratian käsite soveltui monen keskustelijan mielestä LoL:in ja e-urheilun kentälle, kuten kommentissa ID 613: "Pidän pelaamisessa siitä, että se on täydellinen meritokratia, joka on sokea pelaajien identiteeteille[...]." Samanlaisia havaintoja on tehty aiemmissa tutkimuksissa erilaisissa kilpailullisissa peliyhteisöissä muun muassa taistelupelien kentällä (Harper 2013; Thompson 2014).

Keskustelijat argumentoivat naisten kilpailujen sotivan e-urheilun luontaista meritokratiaa vastaan, paapovan naisia tai jopa osoittavan halveksuntaa heidän taitojaan kohtaan. Esiin nousi toisaalta myös kommentteja, joissa naisten kilpailujen nähtiin antavan turvallinen mahdollisuus kilpailla, kunnes pelaajat ovat valmiita "kilpailemaan oikealla lavalla" (ID 613).

Tästä huolimatta vain muutama keskustelija argumentoi, ettei naisten ja miesten välillä pelaajina ole mitään eroa. Ketjussa pohdittiin useaan otteeseen sitä, miksi naiset ylipäänsä pelaavat vähemmän videopelejä kuin miehet. LoL:in sukupuolijakaumasta esitettiin arvauksia, sillä Riot Games ei ole julkaissut omia tilastojaan 
sitten vuoden 2012, jolloin naispelaajien määrä oli 10\%. Useampi kommentti toi esille sen, ettei pelaajien sukupuolesta ole tarkkaa tietoa, ja moni naispelaaja saattaa pitää sukupuolensa salassa. Pisimmät keskustelut (esim. ID 60, jossa oli 293 vastausta) ja pisimmät kommentit (esim. ID 108, jossa oli 756 sanaa) pohtivat, onko naisilla edes mahdollisuutta päästä ammattipelaajiksi, jos joukkueilla on mahdollisuus valita tehtävään mies.

Osa keskustelijoista koki naisten nykyisen aseman olevan ongelmaton ja jopa luonnollinen peliyhteisöissä, kuten ID 76: "yleisesti ottaen naiset eivät ole yhtä kiihkeästi kiinnostuneita peleistä", ja ID 77: "videopelit aktivoivat miehen aivojen mielihyväkeskusta mittavasti enemmän kuin tyttöjen". Vastavuoroisesti muutamissa kommenteissa pohdittiin, että naisilla saattaisi olla etua miehiin nähden kilpailutilanteessa esimerkiksi käsien hienomotoriikasta johtuen (ID 705).

Vaihtoehtoisina näkemyksinä biologisille syille keskustelijat esittivät, ettei nykykulttuuri kannusta naisia pelaamaan tai kilpailemaan kuten miehiä (ID 374), että julkisesti pelaavia naisia seurataan tarkemmin (ID 229), että he kokevat miehiä enemmän häirintää (ID 175), tai että heiltä puuttuu positiivisia roolimalleja (ID 74). Osa kommentoijista taas koki, että syiden pohtiminen asialle on tarkoituksetonta ja olisikin parempi vain "[a]ntaa heidän [naisten] olla huonompia" (ID 115).
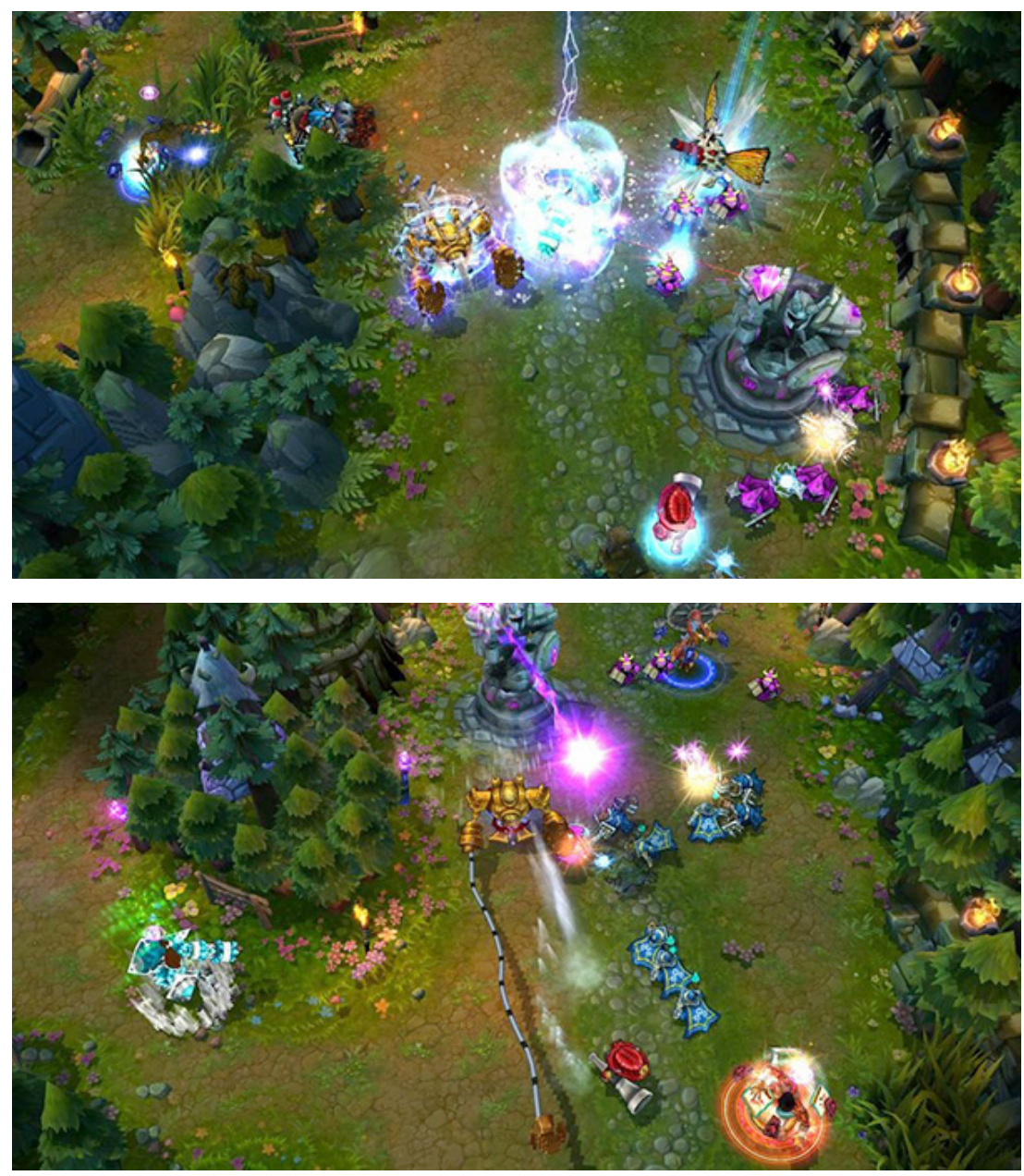

Kuvakaappauksia League of Legends -pelistä. Kuvassa näkyy pelaajien pelihahmoja sekä toisen joukkueen "torni", jonka voi tuhota. Pelissä kaksi viiden hengen joukkuetta pyrkii tuhoamaan toisen joukkueen rakennuksia ja tukikohdan ensimmäisenä. Kuva: Riot Games (2012). 


\section{Team YP naisjoukkueen sponsorina}

Keskusteluketjussa esillä olleen joukkueen sponsori, Mindgeekin omistama pornografinen YouPorn-verkkosivusto, oli keskustelussa esillä ensisijaisesti naisjoukkueen sponsorina. Team YP:n virallisessa tiedotteessa (Team YP 2016) ei ollut lainkaan mainintaa sponsoroinnin rahallisesta arvosta tai odotuksista uudelle joukkueelle, mutta keskustelussa heistä puhuttiin yleensä "ammattilaisina" tarkoittaen heidän kykenevän elämään sponsorointisopimuksen myötä pelaamisesta saamillaan tuloilla. Keskusteluissa kiinnitettiin paljon huomiota kiinnitettyjen pelaajien taitotasoon ja oletettuihin syihin, miksi heitä oli ryhdytty sponsoroimaan. Joukkueen pelaajien taso oli suosittu aihe erityisesti vitsailun kohteena, sillä 85 kommenttia vitsaili joko yksittäisen pelaajan tai koko joukkueen alhaisista sijoituksista.

Suurin osa keskustelijoista pohti joukkueen sponsoroinnin olevan julkisuustempaus. Koko ketjun eniten pisteitä saanut kommentti pohti miten Team YP:n naisjoukkueen sponsorointi vaikuttaa e-urheilun kentällä nyt ja tulevaisuudessa: "saadaan aikaan taas uusi ajanjakso, jolloin pelaavia naisia pilkataan. Erityisesti tämän joukkueen sponsorointisopimuksen vuoksi [...]" (ID 60). Osa kommentoijista kuitenkin koki, että Team YP:n sponsorointisopimus oli palvelus e-urheilulle, sillä se antoi naisille mahdollisuuden pelata ammattimaisesti. Tätä näkemystä heijasti myös Team YP:n oma tiedote:"Me Team YP:ssä uskomme tasavertaiseen mahdollisuuteen kaikille, jonka vuoksi organisaatiomme on haltioitunut päästessään tukemaan LoL:in naisten skeneä. Olemme koonneet oman joukkueemme alan johtavista ja aktiivisesti pelaavista lahjakkuuksista" (Team YP 2016).

Tiedote antaa ymmärtää, että naisjoukkueen hankinta on ennen kaikkea tasaarvoteko, ei niinkään tuottava sponsorointisopimus. Tapaus on mielenkiintoinen, sillä vaikka LCS:n² viralliset säännöt linjaavat, että "[s]ponsorointisopimusten teke-

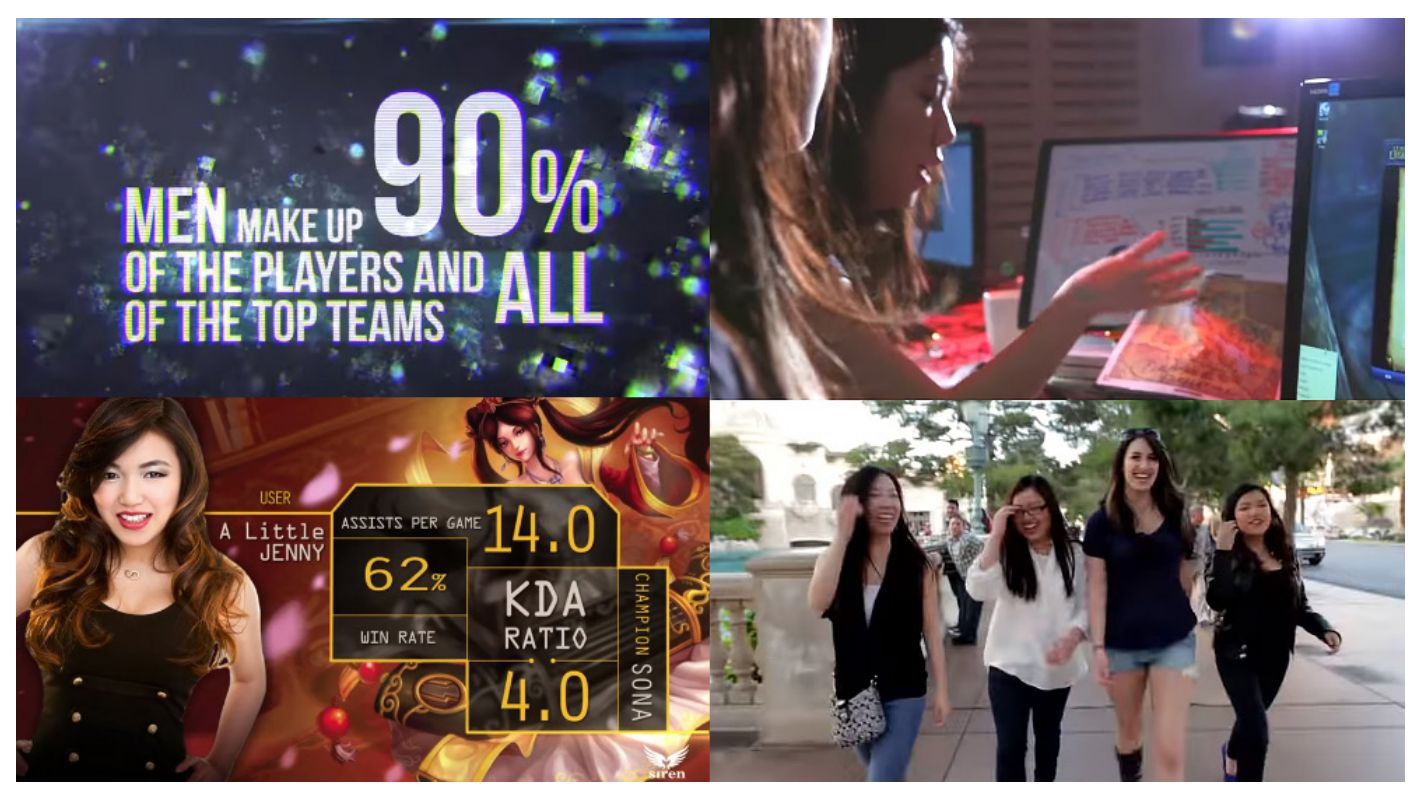

Kuvakaappauksia Team Siren -joukkueen esittelyvideosta. Video esittelee joukkueen pelaajia ja toimintaa joukkueena sekä nostaa esiin LoL:in sukupuolijakauman miesvaltaisuuden. Kuva: TeamSirenGaming 2013.

${ }_{2}^{2}$ LCS eli League Championship Series viittaa LoL-pelin Euroopan ja Pohjois-Amerikan ammattilaissarjoihin. 
mistä ei rajoiteta" (Riot Games 2015, 17), pornografiaan ja muun muassa huumeisiin liittyvät logot ja viittaukset on kielletty virallisissa e-urheilukilpailuissa. LoL:in osalta kilpailevalla joukkueella ei voi siis olla Team YP:n logoa tai nimeä esillä missään muodossa joukkueen pelipaidoissa tai muussa markkinoinnissa. Ylättäen vain muutama kommentoija nosti esiin sen, että kentälle tullut sponsori oli sidoksissa pornoteollisuuteen ja sen brändinhallintaan. Kolmessatoista kommentissa pohdittiin lähinnä neutraalisti joukkueen kiinnittämisen olleen tietoinen valinta Team YP:ltä, sillä järjestäjätahojen sääntöjen vuoksi korkeamman tason joukkueen sponsorointi ei olisi mahdollistanut samaa brändinäkyvyyttä.

\section{Hyvä paha nainen e-urheilijana}

Keskustelijat pohtivat kärkkäästi myös sitä, miten naisen olisi sopiva käyttäytyä pelaajana ja osana e-urheiluyhteisöä. Ero naispelaajien välillä nähtiin muun muassa siinä, miten he tuovat sukupuolensa esille pelatessaan. Kommentti ID 176 ehdottaa että mikäli "hän [naispelaaja] olisi todella keskittynyt pelaamiseen ja [pelin sijoituksissa] kiipeämiseen, en usko että hän kokisi tarvetta tuoda sukupuoltaan esille", kun taas kommentti ID 147 painottaa pelin meritokratian kärsivän, mikäli nainen tuo sukupuolensa esille: "Pelaaminen on yksi harvoista paikoista maailmassa jossa tyttöä voidaan kohdella 100\% reilusti [...] Tämä murenee käsiin jos he menevät verkkoon ja sanovat 'omg tyypit olen tyttö!!'." Omasta sukupuolestaan kertominen kanssapelaajille on kommenttien mukaan jopa odotettavaa käytöstä naisilta, mutta samaan aikaan se sotii heidän uskottavuuttaan vastaan pelaajina.

Asiaa pohtivat ketjussa myös useat naiset. Yksi heistä oli Caitlin "ilysuiteheart" Shloush, entinen ammattipelaaja Team Siren -joukkueesta. Team Siren oli vuonna 2013 perustettu amerikkalainen LoL-naisjoukkue, joka muovasi vahvasti varsinkin LoL:in e-urheiluyhteisön asenteita naisia kohtaan. Joukkue julkaisi 30. toukokuuta 2013 esittelyvideon ${ }^{3}$, joka jaettiin pian sen julkaisun jälkeen r/leagueoflegends-alaosiossa. Videolla tarkasti meikatut pelaajat kertovat intohimoisesti halustaan voittaa ja menestyä LoL:in e-urheilussa sen miesvaltaisuudesta huolimatta. Team Sirenin video poiki muun muassa miljoonia kertoja katseltuja parodiavideoita ja hävityn ottelun LoL-striimaajia ja entisiä ammattilaispelaajia vastaan. Vaikka joukkue ilmoitti lopettavansa toimintansa jo kesäkuussa 2013, se jäi elämään erityisesti Redditin LoLyhteisön sisäpiirivitsinä naisjoukkueiden toimimattomuudesta. Joukkueeseen viittaaminen oli suosittu vitsailun aihe myös tutkimassamme keskusteluketjussa, jossa tasan puolet vitseistä ja ivailusta (73 kommenttia) mainitsi Team Siren -joukkueen.

Kommentissaan (ID 904) Shloush kirjoitti omista kokemuksistaan Team Siren -joukkueessa ja totesi sen olevan esimerkki epäonnistuneesta naisjoukkueesta. Hänen mukaansa olisi parempi kiinnittää sekajoukkueita, jotka pystyvät kilpailemaan luotettavasti, kuin pitää kiinni naisjoukkueista ja naisille suunnatuista kilpailuista. Shloush painotti, että ainoa syy siihen miksi hän ei ollut päässyt LCS-kilpailuihin oli kyvyn puute, ei seksismi. Lopuksi hän pyysi, että ketjun kommentoijat olisivat vihaisia Team YP:lle eivätkä sen kiinnittämille naispelaajille, sillä Shloush koki organisaation käyttävän pelaajia hyväkseen.

Sloushin kommentti vahvistaa näkemystä e-urheilun perustavanlaatuisesta ja ongelmattomasta meritokraattisuudesta sekä amatööri- että ammattilaispuolella. Moni vastasi hyväksyvästi Sloushin synninpäästöön, mutta koki silti, että nais-

\footnotetext{
3 TeamSirenGaming, YouTube, 2013. Introducing Team Siren. <https://www.youtube.com/ watch?v=_Gz9um3wV1o>
} 
pelaajat kuvittelevat itsestään ja taidoistaan liikoja ja käyttävät sukupuoltaan tapana saada huomiota, rahaa tai erityiskohtelua muilta (mies)pelaajilta. Uhka liittyy ennen kaikkea naiseuden käyttämiseen väärin, sillä julkisuustempaukset LoL:in e-urheilussa eivät ole harvinaisia. Esimerkiksi vuonna 2017 pohjoisamerikkalainen Delta Fox -joukkue osallistui LoL:in Challenger Series 2017 -liigaan ${ }^{4}$ joukkueella, johon kuului ainoastaan tunnettuja entisiä ammattilaisia ja suosittuja LoL-striimaajia. Huonosti menestyneen mutta yleisön suosikiksi nousseen joukkueen peittelemätön tarkoitus oli nostaa Delta Foxin franchise-näkyvyyttä eikä menestyä kilpailussa (Bates 2017).

Myös Team YP:n Tanja "Espace" Reither (käyttäjä xTanii Redditissä) osallistui keskusteluun (ID 800). Kommentissaan Reither painotti, että joukkueen tarkoitus oli kilpailla ainoastaan amatööriturnauksissa, ja kuvaili joukkueen olevan "vain 5 tyttöä, jotka pelaavat ja pitävät hauskaa ja yrittävät tulla paremmiksi LoLissa". Kommentti sai viidenneksi suurimman pistemäärän (251) ketjussa, ja suurin osa suorista vastauksista Reitherille oli positiivisia ja kannustavia. Vastaukset olivat sisällöltään selkeästi erilaisia kuin muualla ketjussa, jossa joukkuetta ja sen jäseniä kuvailtiin esimerkiksi liian huonoiksi minkään tason julkiseen kilpailuun. Sekä Sloushin että Reitherin vastaukset ovat anteeksipyytäviä ja vahvistavat muiden kommentoijien näkemystä siitä, että LoL-naisjoukkue voi olla vain joko julkisuustempaus tai täysi fiasko. Myös keskusteluun osallistunut naispelaaja nimeämättömästä sekajoukkueesta koki, että naisjoukkueiden pelaajat ovat laiskoja ja haluavat huomiota (ID 848). "Vihaan, että nämä ihmiset ovat naisten kasvo e-urheilussa ja saavat meidät loput näyttämään hitto vitsiltä", hän jatkaa.

Keskustelun kautta paljastuukin kaksi erilaista naisen mallia e-urheilun kilpakentällä. Naiset voivat näiden mallien mukaan olla joko huonoja naisia, jotka ovat valokeilassa olemattomilla ansioilla ja ujostelemattomasti naisina, tai hyviä naisia, jotka eivät tuo sukupuoltaan esille - varsinkaan yhteydessä pelitaitoonsa. Osa keskusteluun osallistuneista naisista harmitteli varsin suorasukaisesti, että heidät "laitetaan aina yhteen näistä kahdesta kategoriasta. :/" (ID 166).

Kokonaisuudessaan keskusteluketju tarjoaa näkökulman tämänhetkisen e-urheiluyhteisön näkemyksiin siitä, mitä mahdollisuuksia ja rooleja naisille on tarjolla e-urheilun kentällä. Siinä missä osa keskustelijoista odotti naisten lyövän itsensä läpi ammattipelaamisen kentällä hetkenä minä hyvänsä, suurempi osa keskustelijoista tyytyi toteamaan, että naisissa on jotain vialla, ja siksi he eivät ole päässeet minkään e-urheilulajin kärkeen. Esteet ammattilaispelaajaksi pääsemiseen nähtiin henkilökohtaisina hankaluuksina, joihin vastaus on tilanteesta ja sukupuolesta riippumatta kova työ ja pelaamiselle omistautuminen.

Nykytilanne vaikuttaa olevan seurausta sekä uskosta e-urheilussa toteutuvaan oikeudenmukaiseen meritokratiaan, jossa yksilön kyvyt määrittävät tämän menestyksen, että naispelaajien vähäisyydestä varsinkin e-urheilun korkeimman tason kilpailuissa. Joka tapauksessa, kuten Jenson ja Castell (2018) toteavat, naisten aseman parantamiseen ei riitä vain naisten määrän kasvaminen eri e-urheilun ammattilaisrooleissa. On kyettävä huomioimaan ja ymmärtämään maskuliinisen kontrollin kasvu alalla siitä huolimatta, että naiset osallistuvat entistä näkyvämmin e-urheiluun. Pelien ja erityisesti pelaamisen ammattimaistumisen ja tuotteistamisen myötä kehittyvät uudet pelaamisen muodot ja rakenteet ennemminkin kasvattavat sukupuolisia jakolinjoja kuin hajottavat niitä (Jenson \& Castell 2018). Naiset ovat olleet osa pelaajayhteisöjä ja kilpailullista pelaamista jo näiden pelihalleista löytyvien

\footnotetext{
${ }^{4}$ CS eli Challenger Series viittaa puoliammattilaiseen liigaan, jossa kärkijoukkueet kilpailivat pääsystä LCS-liigaan. CS ei ole enää käytössä syyskaudesta 2018 lähtien.
} 
esikuvien aikana, eikä osa vähemmistönä ole vuosien kuluessa juurikaan muuttunut osallistumisen tapojen, mahdollisuuksien ja käytäntöjen muutoksesta huolimatta.

Katsaus perustuu 2018 DiGRA -konferenssissa esitettyyn tutkimukseen. Laajempi artikkeli tutkimuksesta julkaistaan ToDiGRA-lehdessä.

\section{Lähteet}

Bates, J. (2017) The League of Legends Meme Team is a Publicity Stunt -- And It Worked. Comicbook. Saatavilla: <http://wwg.com/league-of-legends/2017/06/11/the-league-of-legends-meme-team-is-apublicity-stunt--and-it-wor/> (viitattu 25.6.2018)

Beavis, C. \& Charles, C. (2007) Would the 'real' girl gamer please stand up? Gender, LAN cafés and the reformulation of the 'girl' gamer. Gender and Education 19(6), 691-705.

Brummett, B. (2009) Techniques of Close Reading. Los Angeles: SAGE.

Cassell, J. \& Jenkins, H. (1998) From Barbie to Mortal Kombat: Gender and Computer Games. Cambridge: MIT Press.

Citizen, J. (2017) Oceanic Women-only eSports league kicks off this weekend. Player Attack. Saatavilla: <https://www.playerattack.com/news/2017/01/19/93052/oceanic-women-esports-league-kicks-offweekend $>$ / (viitattu 25.6.2018)

Cocke, T. (2016) Team YP picks up all-woman League of Legends team. Yahoo! Saatavilla: <https://sports. yahoo.com/team-yp-picks-up-all-woman-league-of-legends-team-184130831.html> (viitattu 25.6.2018)

Cote, A. (2017) “I Can Defend Myself”: Women's Strategies for Coping with Harassment While Gaming Online. Games and Culture, 12(2), 136-155.

Gainsbury, S., Abarbanel, B. \& Blaszczynski, A. (2017) Game On: Comparison of Demographic Profiles, Consumption Behaviors, and Gambling Site Selection Criteria of Esports and Sports Bettors. Gaming Law Review 21(8).

Gray, K., Buyukozturk, B. \& Hill, Z. (2017) Blurring the boundaries: Using Gamergate to examine "real" and symbolic violence against women in contemporary gaming culture. Sociology Compass 11(3).

Harper, T. (2013) The Culture of Digital Fighting Games: Performance and Practice. London: Routledge.

Hsieh, H. F. \& Shannon, S. E. (2005) Three Approaches to Qualitative Content Analysis. Qualitative Health Research 15(9).

Jenson, J. \& de Castell, S. (2018) "The Entrepreneurial Gamer": Regendering the Order of Play. Games and Culture 13(7). <https://doi.org/10.1177/1555412018755913>

Kennedy, J., Meese, J. \& van der Nagel, E. (2016) Regulation and social practice online. Continuum: Journal of Media and Cultural Studies, 30(2), 146-157.

Korhonen, A. (2017) e-urheilu on jääkiekon jälkeen Suomen suosituin urheilulaji. Teknologiainfo. Saatavilla: <http://www.teknologiainfo.com/digitalisaatio/e-urheilu-on-jaakiekon-jalkeen-suomensuosituin-urheilulaji> (viitattu 17.9.2018)

Massanari, A. (2015) Participatory Culture, Community and Play: Learning from Reddit. Digital Formations 75. Frankfurt am Main: Peter Lang.

Massanari, A. (2017) \#Gamergate and The Fappening: How Reddit's algorithm, governance, and culture support toxic technocultures. New Media E Society 19(3), 329-346.

Ratan, R. A., Taylor, N., Hogan, J., Kennedy, T. \& Williams, D. (2015) Stand by Your Man: An Examination of Gender Disparity in League of Legends. Games and Culture 10(5), 438-462.

Richard, G. T. (2016) “Play Like A Girl”: Gender Expression, Sexual Identity, and Complex Expectations in a Female-Oriented Gaming Community. Teoksessa Ruberg, B. ja Shaw, A. (eds.), Queer Game Studies Collection. Minneapolis: University of Minnesota Press, 163-178.

Richard, G. T. \& Hoadley, C. (2013) Investigating a Supportive Online Gaming Community as a Means of Reducing Stereotype Threat Vulnerability Across Gender. Conference paper presented at Games, Learning and Society. Saatavilla: <https://www.researchgate.net/publication/235927581_Investigating_a_ Supportive_Online_Gaming_Community_as_a_Means_of_Reducing_Stereotype_Threat_Vulnerability_Across_Gender> (viitattu 7.11.2018) 
Riot Games (2015) League of Legends Championship Series 2016 Season Official Rules. Saatavilla: <https:// riot-web-static.s3.amazonaws.com/lolesports/Rule $\% 20$ Sets/2016\%20Spring $\% 20$ LCS $\% 20$ Rule $\% 20$ Setv3_01.pdf> (viitattu 25.6.2018)

Riot Games (2012) Summoner's Rift. League of Legends. Saatavilla: <https://na.leagueoflegends.com/en/ media/art/summoners-rift> (viitattu 25.6.2018)

r/leagueoflegends (13.6.2016) Team YP picks up all-woman League of Legends team. Reddit. Saatavilla: <https://redd.it/4nx71k> (arkistoitu 3.8.2017)

Statista 2018a. eSports market revenue worldwide from 2012 to 2021 (in million U.S. dollars). Statista. Saatavilla: <https://www.statista.com/statistics/490522/global-esports-market-revenue/> (viitattu 6.9.2018)

Statista 2018b. eSports audience size worldwide from 2012 to 2021, by type of viewers (in millions). Statista. Saatavilla: <https://www.statista.com/statistics/490480/global-esports-audience-size-viewertype/> (viitattu 6.9.2018)

Taylor, N., Jenson, J. \& de Castell, S. (2009) Cheerleaders/booth babes/Halo hoes: pro-gaming, gender and jobs for the boys. Digital Creativity 20(4), 239-252.

Team YP (13.6.2016) Team YP enters League of Legends. Team YP. Saatavilla: <www.teamyp.com/ team-yp-enters-league-legends/> (viitattu 25.6.2018)

Thompson J. (2014) I'm Better Than You, and I Can Prove it: Games, Expertise, and the Culture of Competition. Väitöskirja. Stanford University.

Vesterby, T. (2004) Speak softly and carry a big gun: A case study of professional female Danish Counter-Strike players. Pro gradu -tutkielma. IT University of Copenhagen. 